\title{
L-carnitine and cancer cachexia. I. L-carnitine distribution and metabolic disorders in cancer cachexia
}

\author{
JAROSŁAW SZEFEL ${ }^{1}$, WIESŁAW JANUSZ KRUSZEWSKI ${ }^{1,2}$, MACIEJ CIESIELSKI ${ }^{1,2}$, \\ MARIUSZ SZAJEWSKI ${ }^{1,2}$, KRZYSZTOF KAWECKI ${ }^{1}$, EWA ALEKSANDROWICZ-WRONA ${ }^{3}$, \\ JERZY JANKUN $^{4,5}$ and WIESŁAWA ŁYSIAK-SZYDŁOWSKA ${ }^{6}$ \\ ${ }^{1}$ Department of Surgical Oncology, Gdynia Oncology Centre, PCK's Maritime Hospital in Gdynia, Gdynia; \\ ${ }^{2}$ Department of Propedeutics of Oncology, Faculty of Health Sciences, Medical University of Gdańsk, Gdańsk; \\ ${ }^{3}$ Department of Clinical Nutrition, Medical University of Gdańsk, Gdańsk, Poland; ${ }^{4}$ Urology Research Center, \\ Department of Urology, The University of Toledo, Health Science Campus, Toledo, OH 43614, USA; \\ ${ }^{5}$ Protein Research Chair, Department of Biochemistry, College of Sciences, King Saud University, \\ Riyadh, Saudi Arabia; ${ }^{6}$ Faculty of Health Sciences, Powiślanski College of Kwidzyń, Kwidzyń, Poland
}

Received March 5, 2012; Accepted April 18, 2012

DOI: $10.3892 /$ or.2012.1804

\begin{abstract}
Cancer cachexia (CC), a progressive loss of body mass, is associated with decreased energy production. Abnormally low levels of L-carnitine (LC) in skeletal muscle means that mitochondrial $\beta$-oxidation of long-chain fatty acids (LCFA) does not occur efficiently in patients with $\mathrm{CC}$. We assessed the influence of CC on LC distribution and the effects of parenteral lipid emulsions on plasma LC levels and urinary excretion. Fifty patients with $\mathrm{CC}$ were randomly assigned to total parenteral nutrition (TPN) with long-chain triglycerides (LCTs), or LCTs plus medium-chain triglycerides (MCTs) as 50/50. Patients were further separated into those with body-mass index $(\mathrm{BMI}) \leq 19 \mathrm{~kg} / \mathrm{m}^{2}$ and BMI $>19 \mathrm{~kg} / \mathrm{m}^{2}$. Plasma concentrations of total LC (TC) and free LC (FC) and their urinary excretion were measured, along with skeletal muscle LC levels. On average, plasma FC and TC were higher than reference values in all patients. Patients with BMI $\leq 19 \mathrm{~kg} / \mathrm{m}^{2}$ had lower plasma FC and TC than those with BMI $>19 \mathrm{~kg} / \mathrm{m}^{2}$. Skeletal muscle FC in the BMI $\leq 19 \mathrm{~kg} / \mathrm{m}^{2}$ group was lower than reference value, but within the normal range in others. LC and FC urinary excretion
\end{abstract}

Correspondence to: Dr Jarosław Szefel, The PCK's Maritime Hospital, Gdynia Oncology Centre, Department of Surgical Oncology, Powstania Styczniowego 1, 81-587 Gdynia, Poland E-mail: jaszefel@mp.pl

Dr Jerzy Jankun, Urology Research Center, Department of Urology, The University of Toledo, Health Science Campus, 3000 Arlington Ave., Toledo, OH 43614, USA

E-mail: jerzy.jankun@utoledo.edu

Key words: L-carnitine, cancer cachexia, lipid emulsion, fatty acid was higher than reference values. Plasma LC and its urinary excretion were higher in patients administered pure LCTs relative to those given MCTs/LCTs. A decrease in skeletal muscle LC in cancer patients with CC (BMI $\left.\leq 19 \mathrm{~kg} / \mathrm{m}^{2}\right)$ correlates with an increase in its plasma levels and increased renal excretion. A diet of MCTs/LCTs reduces LC release from muscle to plasma and urine more effectively than LCTs.

\section{Introduction}

Long-chain fatty acids (LCFA) are a predominant source of energy in the human diet. They make up more than $50 \%$ of caloric intake in patients fed enterally via the gastrointestinal (GI) tract or parenterally and their metabolism takes place in mitochondria. The internal mitochondrial membrane is impermeable to LCFA. Transport of LCFA into the mitochondrial matrix requires L-carnitine (LC), which transports fatty acids via the carnitine shuttle.

The availability of LC determines the efficacy of LCFA $\beta$-oxidation. $\beta$-oxidation is the process by which fatty acids in the form of Acyl-CoA molecules are broken down in mitochondria to generate Acetyl-CoA, the entry molecule for the citric acid cycle.

A decrease in LC levels slows down LCFA oxidation without influencing medium-chain fatty acid (MCFA) oxidation. The largest concentrations of LC are found in skeletal and cardiac muscles, which have a high rate of metabolism of fatty acids. Free LC concentration determines the ratio of CoA to its esters with acyl-CoA.

In clinical practice, LC deficiency leads to skeletal muscle dysfunction and cardiac insufficiency. Along with symptoms such as fatigue, muscle impairment, muscle strain and pain, and cardiomyopathy, states of hypoglycemia, hypoketonemia and hyperammonemia may also be experienced. These disorders disrupt CNS metabolism and may develop further into encephalopathy. It is assumed that a decrease in total LC 
concentration $<20 \mu \mathrm{mol} / 1$ or a relative increase in the ratio of $\mathrm{AC} / \mathrm{FC}>0.4$ is evidence of $\mathrm{LC}$ deficiency $(1,2)$.

Neoplastic disease is associated with the secretion of numerous factors that disrupt cellular energy metabolism and lead to intensification of anaerobic glycolysis and $\beta$-oxidation deceleration $(3,4)$. These disorders lead to adverse energetic balance and cancer cachexia (CC) is the clinical manifestation (5). $\mathrm{CC}$ is associated with muscle mass loss with or without fatty mass loss (6). Muscle mass loss in CC is caused by muscle tissue degradation and fatty mass loss is caused by intensification of lipolysis (7).

Among the recognized mechanisms leading to a decrease in $\mathrm{LC}$ concentration in $\mathrm{CC}$ are: reduced intake of $\mathrm{LC}$, its substrates and cofactors (lysine, methionine, vitamin $\mathrm{C}$, vitamin $\mathrm{B}_{6}$, niacin, $\mathrm{Fe}^{+2}$ ) in the diet and resulting insufficiency of organs taking part in LC synthesis such as the liver, kidneys and brain. Patients with cancer have decreased activity of mitochondrial carnitine O-palmitoyltransferase 1 and 2 (CPT-1 and CPT-2), enzymes that belong to the 'carnitine system' and are responsible for $\beta$-oxidation of LCFA $(8,9)$. Moreover, the consequences and complications of cancer treatment such as chemotherapy, radiotherapy and surgical procedures can also contribute to a decrease in LC (10-13). This study was designed to assess the influence of $\mathrm{CC}$ on $\mathrm{LC}$ distribution and metabolic pathways. Furthermore, we evaluated the differences between the effects of TPN on changes in plasma LC concentration and its excretion in urine on administration of MCT/LCT (50/50 mix) vs. LCT.

\section{Subjects and methods}

Fifty consecutive patients (23 females, 27 males) with advanced cancer and CC and without the ability to feed orally were included in this study. Their mean age was $66 \pm 11$ years.

As a criterion of $\mathrm{CC}$ diagnosis, unintended body mass loss exceeding 5\% in last 6 months was assumed. As a palliative treatment, enteral feeding was surgically restored in these patients. Mean BMI was $21 \pm 5 \mathrm{~kg} / \mathrm{m}^{2}$ and mean body mass loss in the 6 months prior to the study was $22 \pm 9 \%$. Most patients presented water-electrolytic imbalances requiring compensation. All patients required preoperative preparation with use of TPN. Patients with conditions that may have affected LC concentrations independently of $\mathrm{CC}$ were not recruited to this study.

Patients were randomly divided into 2 groups according to the type of lipid emulsion they were administered: MCT/LCT vs. pure LCT. There were no statistically significant differences between these 2 groups regarding age, gender, body mass loss or mean BMI.

Plasma concentrations of LC, specifically TC and FC in plasma and LC excretion in urine, were measured 4 times in all patients: Test 1 on the day of their admission into the study, test 2 on Day 5 of TPN, test 3 on Day 6 of TPN and test 4 on Day 10 of TPN. A sample for FC and TC assay of the rectus abdominis muscle was surgically removed from each patient (during surgery for oncological reason) on the 6th day of hospital stay. No TPN was administered on that day so Day 6 of TPN was actually the 7th day of hospital stay, and so on. Blood samples were taken from the ulnar vein in the morning before TPN administration. Urine samples were obtained as part of the daily collection.

The spectrophotometric method described by Cederblad and co-authors with Salek modification was used to measure the concentrations of LC in plasma, muscle and urine (14-16). Patients being administered MCT/LCT vs. pure LCT differed in terms of mean LC concentration on the day of admission to the study. Because of this, the differences between LC concentration assays 1 and 4 were measured separately for these 2 groups.

For the sake of analysis, patients were also divided into 2 groups according to their BMI: BMI $\leq 19 \mathrm{~kg} / \mathrm{m}^{2}(46 \%)$ and BMI $>19 \mathrm{~kg} / \mathrm{m}^{2}(54 \%)$. There were no statistically significant differences between these 2 groups regarding age, gender and number of patients.

Intralipid (Fresenius-Kabi, Bad Homburg, Germany) was used as pure LCT emulsion and Lipofundin (B. Braun, Melsungen, Germany) was used as an MCT/LCT emulsion. Both emulsions were administered through the central vein catheter by 'all in one' method. Mean energy supply was $25 \mathrm{kcal} / \mathrm{kg}$ and mean protein supply was $1.2 \mathrm{~g} / \mathrm{kg}$.

Ethics. Prior to recruiting patients for this study, we obtained approval from the Independent Bioethics Committee for Scientific Research at Medical University of Gdansk NKEBN/145/2008. All patients included in the study were informed properly about the issues concerning the study and they completed the necessary consent form.

Statistical analysis. Decision-making statistical analysis consisted of testing means using Student's t-test and the comparison of distributions (medians) using the non-parametric U-test, with a special regard to the independence or dependence of variables in both of these tests. Testing was performed in multi-way contingency tables using exact Fisher's test or Pearson $\chi^{2}$ test. The dependence measure was Pearson's correlation coefficient for which the Vanish test was performed. $\mathrm{P}<0.05$ was recognized as statistically significant.

\section{Results}

Mean FC plasma concentration was significantly higher than the reference value in both BMI $\leq 19 \mathrm{~kg} / \mathrm{m}^{2}(\mathrm{P}<0.035)$ and BMI $>19 \mathrm{~kg} / \mathrm{m}^{2}(\mathrm{P}<0.002)$ patient groups (Table I). TC plasma concentration in patients with BMI $>19 \mathrm{~kg} / \mathrm{m}^{2}(\mathrm{P}<0.001)$ was significantly higher than the reference value; it was also higher in patients with BMI $\leq 19 \mathrm{~kg} / \mathrm{m}^{2}$, but the difference did not reach statistical significance $(\mathrm{P}<0.062)$. Both TC $(\mathrm{P}<0.038)$ and FC $(\mathrm{P}<0.041)$ plasma concentrations in patients with BMI $\leq 19 \mathrm{~kg} / \mathrm{m}^{2}$ were significantly lower than in patients with BMI $>19 \mathrm{~kg} / \mathrm{m}^{2}$. Mean $\mathrm{FC} / \mathrm{TC}$ value in the plasma of patients with BMI $\leq 19 \mathrm{~kg} / \mathrm{m}^{2}(0.72 \pm 0.14)$ was similar to that in patients with BMI $>19 \mathrm{~kg} / \mathrm{m}^{2}(0.68 \pm 0.13)$.

FC $(\mathrm{P}<0.035)$ and TC $(\mathrm{P}<0.016)$ excretion in urine in patients with $\mathrm{BMI}>19 \mathrm{~kg} / \mathrm{m}^{2}$ were significantly higher than the reference values. FC $(\mathrm{P}<0.047)$ and TC $(\mathrm{P}<0.068)$ excretion in urine in patients with $\mathrm{BMI} \leq 19 \mathrm{~kg} / \mathrm{m}^{2}$ were also higher than the reference values. There was a significant positive correlation between plasma concentrations of $\mathrm{FC}(\mathrm{r}=0.259 ; \mathrm{P}=0.001)$ and TC $(r=0.339 ; \mathrm{P}=0.001)$ and their urinary excretion. 
Table I. LC concentrations in plasma, muscle and its urinary excretion.

\begin{tabular}{|c|c|c|c|c|}
\hline Studied parameter & $\operatorname{BMI}\left(\mathrm{kg} / \mathrm{m}^{2}\right)$ & Result & Reference value & P-value \\
\hline \multirow{2}{*}{$\begin{array}{l}\text { FC in plasma } \\
(\mu \mathrm{mol} / \mathrm{l})\end{array}$} & $\mathrm{BMI} \leq 19$ & $43 \pm 17$ & \multirow[t]{2}{*}{$36 \pm 6$} & $<0.035$ \\
\hline & BMI $>19$ & $54 \pm 27$ & & $<0.002$ \\
\hline \multirow{2}{*}{$\begin{array}{l}\text { TC in plasma } \\
(\mu \mathrm{mol} / \mathrm{l})\end{array}$} & $\mathrm{BMI} \leq 19$ & $60 \pm 20$ & \multirow[t]{2}{*}{$53 \pm 9$} & $<0.062$ \\
\hline & BMI $>19$ & $79 \pm 36$ & & $<0.001$ \\
\hline \multirow[t]{2}{*}{$\mathrm{FC} / \mathrm{TC}$ ratio in plasma } & $\mathrm{BMI} \leq 19$ & $0.72 \pm 0.14$ & \multirow[t]{2}{*}{$<0.80$} & NS \\
\hline & BMI $>19$ & $0.68 \pm 0.13$ & & NS \\
\hline \multirow{2}{*}{$\begin{array}{l}\text { Urinary excretion of FC } \\
(\mu \mathrm{mol} / \mathrm{g} \text { of creatinine })\end{array}$} & $\mathrm{BMI} \leq 19$ & $274 \pm 309$ & \multirow[t]{2}{*}{$166 \pm 151$} & $<0.047$ \\
\hline & BMI >19 & $290 \pm 311$ & & $<0.035$ \\
\hline \multirow{2}{*}{$\begin{array}{l}\text { Urinary excretion of TC } \\
(\mu \mathrm{mol} / \mathrm{g} \text { of creatinine })\end{array}$} & $\mathrm{BMI} \leq 19$ & $428 \pm 375$ & \multirow[t]{2}{*}{$284 \pm 192$} & $<0.068$ \\
\hline & BMI $>19$ & $543 \pm 475$ & & $<0.016$ \\
\hline \multirow{2}{*}{$\begin{array}{l}\text { FC in muscle } \\
(\mu \mathrm{mol} / \mathrm{g} \text { of muscle })\end{array}$} & $\mathrm{BMI} \leq 19$ & $3.5 \pm 3.3$ & \multirow[t]{2}{*}{$5.5 \pm 2.3$} & $<0.011$ \\
\hline & BMI $>19$ & $5.0 \pm 4.7$ & & NS \\
\hline \multirow{2}{*}{$\begin{array}{l}\text { TC in muscle } \\
(\mu \mathrm{mol} / \mathrm{g} \text { of muscle })\end{array}$} & $\mathrm{BMI} \leq 19$ & $4.5 \pm 4.1$ & \multirow[t]{2}{*}{$6.4 \pm 2.6$} & $<0.049$ \\
\hline & $\mathrm{BMI}>19$ & $5.9 \pm 5.2$ & & NS \\
\hline \multirow[t]{2}{*}{$\mathrm{FC} / \mathrm{TC}$ ratio in muscle } & $\mathrm{BMI} \leq 19$ & $0.75 \pm 0.16$ & \multirow[t]{2}{*}{$0.85 \pm 0.07$} & $<0.014$ \\
\hline & BMI $>19$ & $0.84 \pm 0.09$ & & NS \\
\hline
\end{tabular}

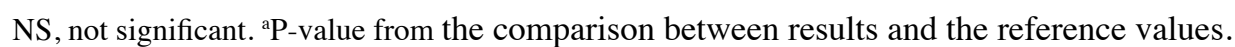

Table II. Relationship between type of lipid emulsion and changes in TC and FC concentrations.

\begin{tabular}{|c|c|c|c|c|}
\hline & \multicolumn{2}{|c|}{$\mathrm{MCT} / \mathrm{LCT}$} & \multicolumn{2}{|c|}{ LCT } \\
\hline & Test 1 & Test 4 & Test 1 & Test 4 \\
\hline Plasma FC ${ }^{\mathrm{a}}(\mu \mathrm{mol} / \mathrm{l})$ & $56 \pm 22$ & $42 \pm 19^{b}$ & $45 \pm 25$ & $41 \pm 15$ \\
\hline Plasma $\mathrm{TC}^{\mathrm{a}}(\mu \mathrm{mol} / \mathrm{l})$ & $79 \pm 32$ & $59 \pm 27^{\mathrm{b}}$ & $65 \pm 30$ & $56 \pm 21$ \\
\hline Plasma FC/TC ratio & $0.71 \pm 0.12$ & $0.70 \pm 0.12$ & $0.69 \pm 0.15$ & $0.74 \pm 0.12$ \\
\hline Urine $\mathrm{FC}(\mu \mathrm{mol} / \mathrm{g}$ of creatinine) & $364 \pm 312$ & $384 \pm 479$ & $233 \pm 299$ & $189 \pm 232$ \\
\hline Urine $\mathrm{TC}(\mu \mathrm{mol} / \mathrm{g}$ of creatinine $)$ & $591 \pm 483$ & $596 \pm 587$ & $429 \pm 392$ & $328 \pm 311$ \\
\hline
\end{tabular}

${ }^{\mathrm{a}} \mathrm{P}<0.05$ for the difference (T1-T4) MCT/LCT vs. (T1-T4) LCT; ${ }^{\mathrm{b}} \mathrm{P}<0.051 \mathrm{vs.} 4$ for MCT/LCT

FC and TC concentrations in muscle were significantly lower than the reference values in patients with BMI $\leq 19 \mathrm{~kg} / \mathrm{m}^{2}$, and fitted within the reference values range in patients with $\mathrm{BMI}>19 \mathrm{~kg} / \mathrm{m}^{2}$. FC/TC ratios in skeletal muscle tissue were significantly different between these 2 groups $(\mathrm{P}<0.013)$. Muscle $\mathrm{FC} / \mathrm{TC}$ ratio in patients with BMI $\leq 19 \mathrm{~kg} / \mathrm{m}^{2}$ was significantly higher than the reference value $(\mathrm{P}<0.014)$.

The influence of LCT and MCT/LCT emulsions on TC concentration changes in plasma and urine. There were significant reductions in plasma TC $(\mathrm{P}<0.004)$ and FC $(\mathrm{P}<0.002)$ concentrations between tests 1 and 4 in patients receiving MCT/LCT emulsion. Reductions were not significant in patients receiving LCT emulsion.
Reductions in plasma TC $(\mathrm{P}<0.048)$ and FC $(\mathrm{P}<0.014)$ concentrations between tests 1 and 4 in the MCT/LCT group were significantly higher than in the LCT group. There were no significant differences in the influence of the 2 emulsions on TC and FC urinary excretion (Table II).

\section{Discussion}

$\mathrm{CC}$ is often accompanied by anorexia and changes in alimentary habits, including revulsion to meat, the main source of LC. Precursors indispensible to LC synthesis also appear to be in short supply in $\mathrm{CC}$, including methionine, lysine, vitamin $\mathrm{C}$, vitamin $\mathrm{B}_{6}$, niacin, $\mathrm{Fe}^{+2}$ and others $(17,18)$.

The other consequences of $\mathrm{CC}$ are an intensification of acute phase proteins synthesis and growth of primary tumor 
and metastases. These processes compete with LC synthesis for the same substrates i.e. lysine and methionine. Because of these limitations in LC supply and its endogenous synthesis, plasma LC concentration in patients with $\mathrm{CC}$ is reduced as previously shown by Malaguarnera et al (19). These authors suggested that since most of the patients in their study had previously undergone chemotherapy or radiotherapy, this may have led to renal tubule damage, thus limiting LC reabsorption. However, we believe that competition for the LC substrates lysine and methionine due to intensified protein synthesis is a more likely explanation for reduced LC concentrations observed in their study.

This study was designed to enquire whether CC disrupts LC distribution and metabolism in the human body. Contrary to previous results $(22,23)$, LC plasma concentrations in our study significantly exceeded the reference value and simultaneously also exceeded the renal threshold (Table I).

In the group of patients with BMI $\leq 19 \mathrm{~kg} / \mathrm{m}^{2}$, mean LC plasma concentration was significantly lower than in patients with BMI $>19 \mathrm{~kg} / \mathrm{m}^{2}$, but renal excretion in both groups exceeded both the upper limit of the reference value and the renal threshold (Table I).

From previous studies, it is known that $\mathrm{AC}$ and $\mathrm{FC}$ excretion begin to increase instantly after exceeding the threshold level. This is because healthy kidneys reabsorb more LC to compensate for the decrease in plasma concentrations $(20,21)$. It should be also emphasized that the renal threshold for LC is only slightly higher than the upper limit of the reference value. In our study we noted a significant positive correlation between $\mathrm{FC}(\mathrm{r}=0.259 ; \mathrm{P}=0.001)$ and $\mathrm{TC}$ $(\mathrm{r}=0.339 ; \mathrm{P}=0.001)$ plasma concentrations and their urinary excretion.

In our study, FC $(\mathrm{p}<0.011)$ and TC $(\mathrm{P}<0.049)$ muscle concentrations in patients with BMI $\leq 19 \mathrm{~kg} / \mathrm{m}^{2}$ were significantly lower than the bottom limit of the reference value, and were directly correlated with the extent of malnutrition (Table I). Because almost $98 \%$ of the body's LC content is located in the muscles, a decrease in LC muscle concentration is a reflection of a decrease in overall body content and a consequently decreased ability of LC to participate in FA metabolism.

We have observed that LC muscle and plasma concentrations and changes in urinary excretion in the studied group of patients are logically interrelated. Muscle LC, when released, appears in plasma. Therefore, a decrease in LC muscle concentration is associated with its increase in plasma. An increase in LC plasma concentration, especially above the renal threshold, increases its urinary excretion. Mechanical muscle injury associated with laparotomy also releases LC; the temporary ischemia of surgical wounds exerts a similar effect. We believe that these are the possible reasons for the increase in transient LC plasma concentration and its renal excretion between tests 2 and 3 . Since this phenomenon affects all patients to a similar extent, it should not influence a comparative analysis of the results.

Our study proves that in spite of LC plasma concentrations exceeding the reference value, LC muscle concentration actually decreases. This appears to be a situation without a previously recognized equivalent in the human body.
According to the definition of $\mathrm{CC}$, it is associated with muscle mass loss due to muscle degradation, mostly myosin heavy chains (MyHC) $(22,23)$. TNF- $\alpha$, IL-1 $\beta$, IL-6 and IFN- $\gamma$ are the main factors responsible for muscle degradation $(24,25)$. Activation of the ubiquitin-proteasome system is the final step of this process (26-29). It is worth mentioning that muscle degradation in CC is significantly different from muscle loss due to necrosis or rhabdomyolysis.

Our study also reveals that the concentration of LC in muscle decreases as the stage of $\mathrm{CC}$ advances in cancer patients i.e. as their BMI lowers. Therefore, LC muscle concentration might be both a useful marker to evaluate the extent of muscle degradation and an objective indicator of current CC stage in cancer patients.

Furthermore, we observed that the plasma $\mathrm{AC} / \mathrm{FC}$ ratio was higher than the reference value in both patients with $\mathrm{BMI}$ $\leq 19 \mathrm{~kg} / \mathrm{m}^{2}$ and BMI $>19 \mathrm{~kg} / \mathrm{m}^{2}$ (Table I). When the AC/FC ratio in the plasma crosses the upper limit of the reference value in clinical practice, it is considered detrimental from the point of view of long-chain FA metabolism. On the other hand, we also observed increased FC concentrations above the reference value (Table I). Theoretically, this should be evidence for an increase in LC availability for FA transport through the mitochondrial membrane and their introduction to $\beta$-oxidation.

Based on our results we can conclude that an increase in FC plasma concentration with an accompanying decrease in muscle concentration do not translate into better metabolic utility of LC, because FA metabolism takes place mainly in myocytes.

This suggests that AC and FC assays may be more useful diagnostically if they are carried out in muscle than in plasma. Therefore, in certain cases more invasive methods than blood and urine tests should be considered; muscle biopsies may provide more accurate results.

With regard to the influence of lipid emulsion on LC distribution in the body and metabolism in patients with $\mathrm{CC}$, we noted a significant decrease in LC plasma concentration in patients receiving MCT/LCT. The decrease was not significant in patients receiving LCT (Table II). Administration of MCT/ LCT demands less LC involvement in LCFA metabolism and may be preferable to LCT in CC patients because it limits LC release from muscles to plasma. This indirectly suggests that MCT/LCT may decrease the process of muscle degradation in comparison with LCT.

CC leads to a general deficiency in LC that correlates with the extent of patient malnutrition. The main cause of this deficiency is likely to be skeletal muscle degradation. A decrease in LC muscle concentration correlates with its increase in plasma and urinary excretion. Therefore, skeletal muscle concentration is a true reflection of LC deficiency in $\mathrm{CC}$ patients, and not plasma or urine levels.

The absence of significant increases in LC plasma concentrations in patients receiving MCT/LCT lipid emulsion in TPN suggests that it reduces the degradation of skeletal muscles in comparison with pure LCT emulsion.

LC concentration assay in muscles may be a useful marker to evaluate the process of skeletal muscle degradation, along with being an objective marker of $\mathrm{CC}$ stage in cancer patients. 


\section{Acknowledgements}

This study was supported by the Fundacja na Rzecz Rozwoju Chirurgii 'Viribus Unitis' im. Profesora Jankaua. Fundacja Pożytku Publicznego, Gdynia, Poland.

\section{References}

1. Alberty R and Albertyova D: Biological variation of free and total carnitine in serum of healthy subjects. Clin Chem 43: 2441-2443, 1997.

2. Marin VB, Azocar M, Molina M, Guerrero JL, Ratner R and Cano F: Total carnitine and acylated carnitine ratio: relationship of free carnitine with lipid parameters in pediatric dialysis patients. Adv Perit Dial 22: 130-135, 2006.

3. Locasale JW and Cantley LC: Altered metabolism in cancer. BMC Biol 8: 88, 2010.

4. Hsu PP and Sabatini DM: Cancer cell metabolism: Warburg and beyond. Cell 134: 703-707, 2008.

5. Fouladiun M, Körner U, Bosaeus I, Daneryd P, Hyltander A and Lundholm KG: Body composition and time course changes in regional distribution of fat and lean tissue in unselected cancer patients on palliative care - correlations with food intake, metabolism, exercise capacity, and hormones. Cancer 103: 2189-2198, 2005 .

6. Fearon K, Strasser F, Anker SD, et al: Definition and classification of cancer cachexia: an international consensus. Lancet Oncol 12: 489-495, 2011

7. Agustsson T, Ryden M, Hoffstedt J, et al: Mechanism of increased lipolysis in cancer cachexia. Cancer Res 67: 5531-5537, 2007.

8. Rasmussen BB, Holmback UC, Volpi E, Morio-Liondore B, Paddon-Jones D and Wolfe RR: Malonyl coenzyme A and the regulation of functional carnitine palmitoyltransferase-1 activity and fat oxidation in human skeletal muscle. J Clin Invest 110: 1687-1693, 2002.

9. Saks V, Favier R, Guzun R, Schlattner U and Wallimann T: Molecular system bioenergetics: regulation of substrate supply in response to heart energy demands. J Physiol 577: 769-777, 2006.

10. Peluso G, Nicolai R, Reda E, Benatti P, Barbarisi A and Calvani M: Cancer and anticancer therapy-induced modifications on metabolism mediated by carnitine system. J Cell Physiol 182: 339-350, 2000

11. Mancinelli A, D'Iddio S, Bisonni R, Graziano F, Lippe P and Calvani M: Urinary excretion of L-carnitine and its short-chain acetyl-L-carnitine in patients undergoing carboplatin treatment. Cancer Chemother Pharmacol 60: 19-26, 2007.

12. McGough C, Baldwin C, Frost G and Andreyev HJ: Role of nutritional intervention in patients treated with radiotherapy for pelvic malignancy. Br J Cancer 90: 2278-2287, 2004.
13. Pezner R and Archambeau JO: Critical evaluation of the role of nutritional support for radiation therapy patients. Cancer 55: 263-267, 1985

14. Cederblad G, Harper P and Lindgren K: Spectrophotometry of carnitine in biological fluids and tissue with a Cobas Bio centrifugal analyzer. Clin Chem 32: 342-346, 1986.

15. Sałek J, Mierzejewski P, Wąsewicz M, Uszycka-Karcz M and Łysiak-Szydłowska W: Karnityna surowicy i moczu, próba monitorowania terapii karnityną. Diagn Lab 25: 109-118, 1989 (In Polish).

16. Debska S, Kawecka A, Wojnarowski K, et al: Correlation between plasma carnitine, muscle carnitine and glycogen levels in maintenance hemodialysis patients. Int J Artif Organs 23: 90-96, 2000

17. Rebouche CJ and Engel AG: Tissue distribution of carnitine biosynthetic enzymes in man. Biochim Biophys Acta 630: 22-29, 1980 .

18. Rebouche CJ: Sites and regulation of carnitine biosynthesis in mammals. Fed Proc 41: 2848-2852, 1982.

19. Malaguarnera M, Risino C, Gargante MP, et al: Decrease of serum carnitine levels in patients with or without gastrointestinal cancer cachexia. World J Gastroenterol 12: 4541-4545, 2006.

20. Eanes RZ and Biniek RL: The twenty-four-hour urinary excretion of carnitine and creatinine in normal and hypothyroid children. Biochem Med 24: 110-117, 1980.

21. Evans AM and Fornasini G: Pharmacokinetics of L-carnitine. Clin Pharmacokinet 42: 941-967, 2003.

22. Acharyya S, Ladner KJ, Nelsen LL, et al: Cancer cachexia is regulated by selective targeting of skeletal muscle gene products. J Clin Invest 114: 370-378, 2004

23. Clark KA, McElhinny AS, Beckerle MC and Gregorio CC: Striated muscle cytoarchitecture: an intricate web of form and function. Annu Rev Cell Dev Biol 18: 637-706, 2002.

24. Karayiannakis AJ, Syrigos KN, Polychronidis A, Pitiakoudis M, Bounovas A and Simopoulos K: Serum levels of tumor necrosis factor-alpha and nutritional status in pancreatic cancer patients. Anticancer Res 21: 1355-1358, 2001.

25. Matthys P, Dijkmans R, Proost P, et al: Severe cachexia in mice inoculated with interferon-gamma-producing tumor cells. Int J Cancer 49: 77-82, 1991 .

26. Lecker SH, Solomon V, Mitch WE and Goldberg AL: Muscle protein breakdown and the critical role of the ubiquitinproteasome pathway in normal and disease states. J Nutr 129: S227-S237, 1999.

27. Eley HL and Tisdale MJ: Skeletal muscle atrophy, a link between depression of protein synthesis and increase in degradation. J Biol Chem 282: 7087-7097, 2007.

28. Tisdale MJ: Mechanisms of cancer cachexia. Physiol Rev 89: 381-410, 2009.

29. Khal J, Hine AV, Fearon KC, Dejong $\mathrm{CH}$ and Tisdale MJ: Increased expression of proteasome subunits in skeletal muscle of cancer patients with weight loss. Int J Biochem Cell Biol 37: 2196-2206, 2005. 